\title{
Correction to: The Effects of Mobile-App-Based Low- Carbohydrate Dietary Guidance on Postprandial Hyperglycemia in Adults with Prediabetes
}

\author{
Xiaoyu Chen · Haihua Su • Daisuke Kunii - Kousuke Kudou • \\ Yiyan Zhang · Ying Zhao · Dan Zhang · Yuanyuan Xing • \\ Jiaqi Teng · Zhiqiang Nie · Xinxin Liu · Kaijun Niu • Yong Zhao • \\ Qi Guo (D)
}

Published online: January 17, 2021

(C) The Author(s) 2021

Correction to: Diabetes Ther (2020) 11:2341-2355

https://doi.org/10.1007/s13300-020-00906-x

In the original article, The corresponding author details were missing. The corresponding author name is Q. Guo and his email address is guoqijp@gmail.com.

The original article has been corrected.

Open Access. This article is licensed under a Creative Commons Attribution-NonCommercial 4.0 International License, which

The original article can be found online at https://doi. org/10.1007/s13300-020-00906-X.

\footnotetext{
X. Chen

Department of Rehabilitation Medicine, TEDA International Cardiovascular Hospital,

Cardiovascular Clinical College of Tianjin Medical

University, Tianjin, China

X. Chen

Department of Rehabilitation Medicine, Tianjin

Medical University, Tianjin, China

H. Su · D. Zhang · Y. Xing · J. Teng

Department of Endocrinology and Nephrology, PKU

Care CNOOC Hospital, Tianjin, China

D. Kunii · Y. Zhang

Department of Food and Nutritional Sciences, Jumonji University, Tokyo, Japan
}

permits any non-commercial use, sharing, adaptation, distribution and reproduction in any medium or format, as long as you give appropriate credit to the original author(s) and the source, provide a link to the Creative Commons licence, and indicate if changes were made. The images or other third party material in this article are included in the article's Creative Commons licence, unless indicated otherwise in a credit line to the material. If material is not included in the article's Creative Commons licence and your intended use is not permitted by statutory regulation or exceeds the permitted use, you will need to obtain permission directly from the copyright holder. To view a copy of this licence, visit http:// creativecommons.org/licenses/by-nc/4.0/.

\footnotetext{
K. Kudou

Japan Nutrition Care Service Association, Tokyo, Japan

Y. Zhao $\cdot$ Z. Nie $\cdot$ X. Liu

Department of Rehabilitation Medicine, PKU Care CNOOC Hospital, Tianjin, China

K. Niu

School of Public Health, Tianjin Medical University, Tianjin, China

Y. Zhao · Q. Guo (ه)

Department of Rehabilitation Medicine, Shanghai

University of Medicine and Health Sciences

Affiliated Zhoupu Hospital, Shanghai, China

e-mail: guoqijp@gmail.com
} 